\title{
PAISAJES DE LOS SECANOS CEREALISTAS DE CASTILLA Y LEÓN ${ }^{1}$
}

\author{
Milagros ALARIO TRIGUEROS \\ Departamento de Geografía. Universidad de Valladolid
}

\author{
Recibido: 08/03/2011
}

Aceptado: 21/06/2011

RESUMEN: La imagen de Castilla es la imagen de los paisajes de secanos cerealistas. Llanuras sin fin que se extienden hasta el horizonte y que se definen por la horizontalidad monótona y monocroma de campos de cereal, salpicados cada poco de pequeños núcleos de población, marcados hoy por el envejecimiento y el abandono. Paisajes melancólicos y calmos que son el resultado de un proceso de especialización productiva desarrollado a lo largo del último siglo y que ha condicionado sus formas externas así como sus sistemas de producción, provocando la disfuncionalidad de una gran parte de los elementos tradicionales del paisaje y la aparición de otros nuevos.

PALABRAS CLAVE: horizontalidad, especialización productiva, disfuncionalidad.

\section{LANDSCAPES OF THE DRYLAND CEREAL OF CASTILE AND LEON}

ABSTRACT: The image of Castilla is the image of the landscape of dry cereal. The endless plains that stretch to the horizon and are defined by the monotonous and monochrome horizontal grain fields, interspersed every bit of small villages, marked today by the aging people and the abandonment. Melancholic and quiet landscapes that are the result of a specialized production process developed over the last century, which has conditioned its external forms and their production systems, resulting in the dysfunction of a large part of the traditional elements of landscape and the emergence of new ones.

KEY WORDS: horizontal skyline, specialized production, lack of functionality.

\section{INTRODUCCIÓN}

En el imaginario social y colectivo, pensar en Castilla es pensar en las llanuras cerealistas extensas y homogéneas. La imagen de la "Castilla en es-

\footnotetext{
${ }^{1}$ Aportación realizada en el marco del Proyecto Estudio de los paisajes arquetipo de la agricultura en Castilla y León, Ref. VA038A09 de la Consejería de Cultura de la Junta de Castilla y León; del Proyecto de I+D+i Las unidades básicas de paisaje agrario en España: Identificación, caracterización y valoración. La España Interior, Septentrional y Occidental (REF: CSO2009-12225-C05-01); del Grupo de Investigación Registrado (GR.156) de la Junta de Castilla y León y de la Estrategia Regional de Investigación Científica, Desarrollo, Tecnológico e Innovación 2007-2013.
} 
combros" desarrollada por Julio Senador a partir de las reflexiones del regeneracionismo de finales del siglo XIX crea esa imagen de la región dura y triste atada a las producciones agrarias de secanos cerealistas que producen hombres endurecidos en su lucha contra unas condiciones físicas hostiles.

Figura 1. Áreas de cultivos herbáceos de secano dominantes

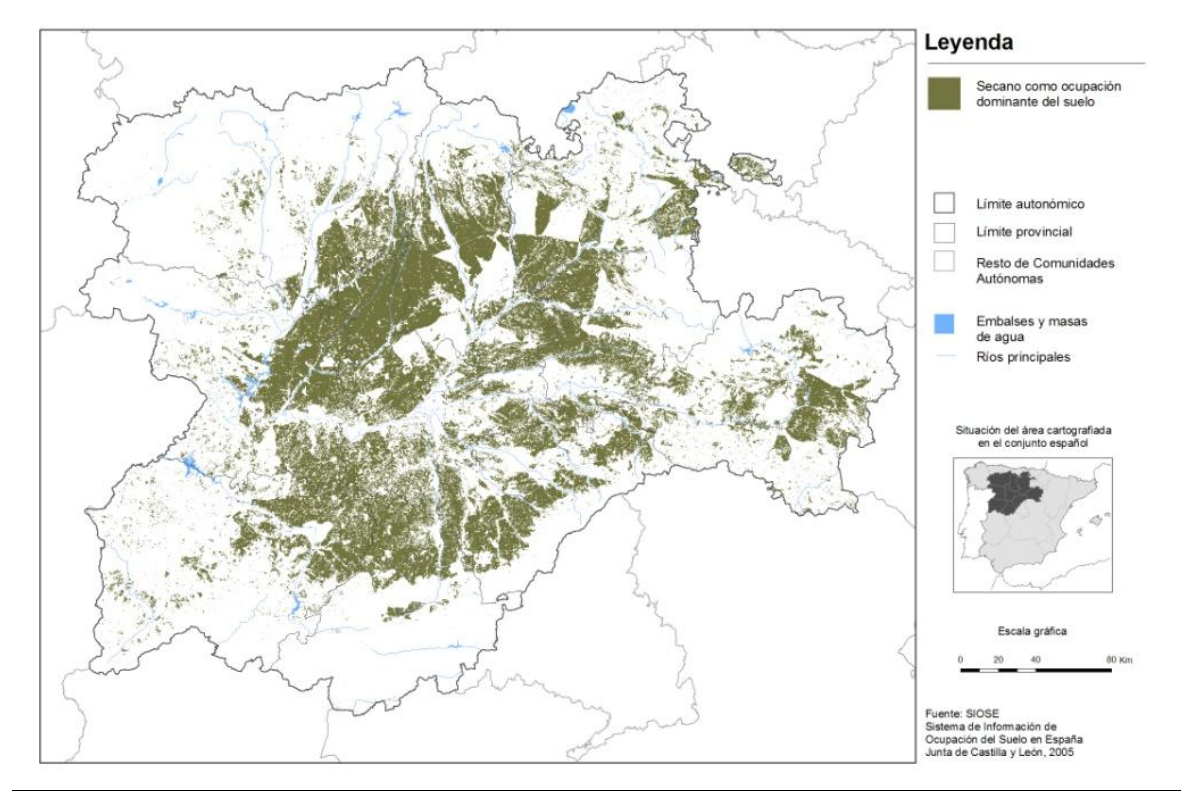

FUENTE: SIOSE. Elaboración Juan Carlos Guerra.

No hay duda de que en el contexto de la actual comunidad autónoma de Castilla y León, las llanuras de la cuenca del Duero constituyen la parte fundamental de su territorio y definen básicamente su imagen exterior. Los espacios montañosos, tan importantes en el norte y el sur, se piensan más vinculados a las comunidades vecinas (fundamentalmente a Cantabria y Asturias por el norte y a Madrid y Extremadura por el Sur), y las penillanuras del oeste de la comunidad, con tener una fuerte personalidad, no han generado una imagen identitaria de Castilla, ya que sus modelos productivos fundamentales, las dehesas, aparecen en el imaginario colectivo más relacionadas con la vecina Extremadura.

Las áreas de llanura constituyen más de dos tercios de la superficie regional. No todas ellas podemos definirlas directamente como espacios de producción predominantemente de herbáceos extensivos, ya que en parte de ellas aparecen otros cultivos y producciones fundamentales en su paisaje: regadíos cerealistas o forrajeros, viñedos de alta especialización..., pero la gran mayoría de los paisajes agrarios más extendidos superficialmente están 
vinculados a esta orientación cultural, de forma que unos 3 millones de ha pueden ser definidas como sistemas herbáceos extensivos en Castilla y León (ÁLVAREZ. 2007: 18).

Desde el centro de la cuenca del Duero en Valladolid, en un radio de unos 100/120 km hacia cualquiera de los puntos cardinales, los paisajes agrarios dominantes son los paisajes del cereal de secano. La Tierra de Campos vallisoletana y palentina, El Cerrato y los Montes de Torozos, la zamorana Tierra del Pan, las Campiñas del sur del Duero...son comarcas de alto valor simbólico en Castilla y León cuyos paisajes están predominantemente marcados por las producciones herbáceas.

\section{HOMOGENEIDAD Y MONOTONÍA PAISAJÍSTICAS COMO CLAVES}

Horizontalidad, monotonía, aspereza y desolación, son adjetivos vinculados a las descripciones de las llanuras castellanas desde hace siglos:

“...inmensas soledades, que no carecen de poesía, hacen pensar en el océano, cuya grandiosidad tienen. También recuerdan el desierto, sobre todo cuando se ven, perdiéndose de vista en la lejanía, algunas filas de mulas que levantan grandes nubes de polvo, como lo haría una caravana en el Sahara" (Jean-Charles DAVILLIER, 1862) (GARCÍA, 1999: 176)

"El día fue por demás caluroso y con mucha lentitud proseguimos la marcha a través de las llanuras de Castilla la Vieja. Grandes son sus montañas y no menos grandes sus planicies, ilimitadas, al parecer...Aqui y allá se encuentra a veces algún labriego solitario trabajando la tierra; tierra sin límites, donde los olmos, las encinas y los fresnos son desconocidos; tierra sin verdor, sobre la que sólo el triste desolado pino destaca su forma piramidal" (Georges BORROW 1842)" (GARCÍA, 1999: 15-16).

“... con sus campos trigueros, sin setos ni árboles, limitados sólo por el bajo horizonte, y sus llanuras sin cultivo ni habitantes, abandonadas a las flores silvestres y a las abejas, y que se vuelven melancólicas aún con el espectáculo de castillos o aldeas arruinados, levantándose como esqueletos calcinados de su antigua vitalidad... sombría monotonía y abominación desolada en la que ninguna sonrisa saludará la llegada del viajero y ninguna lágrima correrá cuando marche" (FORD en BLAZQUEZ, 2010).

Imágenes que, sin duda con una base de realidad, han trascendido al arte y la literatura. Así Unamuno escribía en 1902 "Recórrense a las leguas y más leguas desiertas sin divisar apenas más que la llanura inacabable donde 
verdea el trigo o amarillea el rastrojo, alguna procesión monótona y grave de pardas encinas, de verde severo y perenne, que pasan lentamente espaciadas, o de tristes pinos que levantan sus cabezas uniformes. De cuando en cuando, a la orilla de algún pobre regato medio seco o de un río claro, unos pocos álamos, que en la soledad infinita adquieren vida intensa y profunda. De ordinario anuncian estos álamos al hombre: hay por alli algún pueblo, tendido en la llanura al sol, tostado por éste y curtido por el hielo, de adobes muy a menudo, dibujando en el azul del cielo la silueta de su campanario" (en ORTEGA, 2009: 45)

Las razones básicas de estas características tienen que ver, por un lado con las condiciones físicas de las que deriva la planitud dominante y, por otro, con los procesos de roturación masiva que abrieron las vistas a lo largo de kilómetros.

\section{La planitud de llanuras estructurales y erosivas}

Los movimientos tectónicos terciarios y los procesos subsiguientes de desnivelación, erosión y relleno sedimentario, son los responsables de unas formas de relieve que, en el conjunto del territorio de la actual comunidad de Castilla y León, se estructuraN en un conjunto variado de llanuras enmarcadas por un perímetro montañoso de unos $1.500 \mathrm{~km}$ de longitud (CASCOS, 1992: 8).

Figura 2. Paisaje castellano. Félix Antonio González

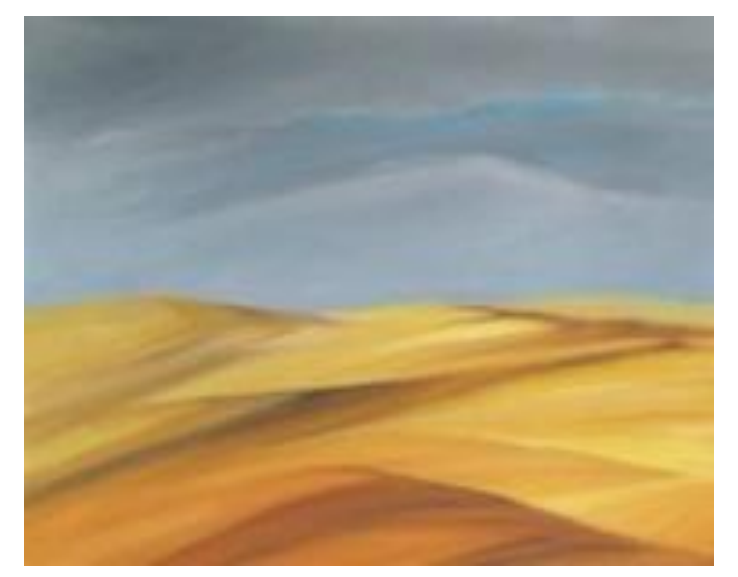

El sector de las llanuras sedimentarias, a pesar de su diversidad genética, de edad y de altitud, comparte como característica fundamental la horizontalidad de sus formas, con leves ondulaciones en algunos casos. Horizontalidad cuyas claves se encuentran en la disposición de sus estratos y en la escasa capacidad de tajo del la red del Duero (CASCOS, 1992: 14)

Según Cascos Maraña se pueden distinguir en este conjunto dos tipos de llanuras: la cuenca sedimentaria propiamente y las plataformas detríticas. Las primeras, mayoritarias en extensión, corresponden a espacios de relleno terciario en estratos horizontales de arenas, arcillas, margas y, en el centro y este de la cuenca, calizas. La 
existencia o no de ese recubrimiento calizo provoca la diferencia entre los páramos, plataformas horizontales elevadas en torno a unos 800-1.100 m, y las campiñas, llanuras erosivas cuya altitud oscila entre $10 \mathrm{~s} 700 \mathrm{~m}$ en el centro de la cuenca y los $1000 \mathrm{~m}$. en los bordes. Las plataformas detríticas, por otro lado, constituyen llanuras escalonadas entre los 1000-1250 m. de las más antiguas y periféricas y los entre 700-950 m de las terrazas de la red del Duero. De gran perfección, son el producto de depósitos sobre llanuras de páramo o campiña de canturral arrastrado por los ríos. (CASCOS, 1992: 14$15)$.

A pesar de las diferencias Figura 3. Paisaje castellano: El Aliste. M. señaladas, en lo morfológico el resultado es muy homogéneo ya que se trata siempre de formas horizontales que, aunque con condiciones edáficas y climáticas distintas, han constituido la base de aprovechamientos muy similares basados, en todos los casos, en el predominio del cereal. Aprovechamiento hoy dominante y casi excluAlario

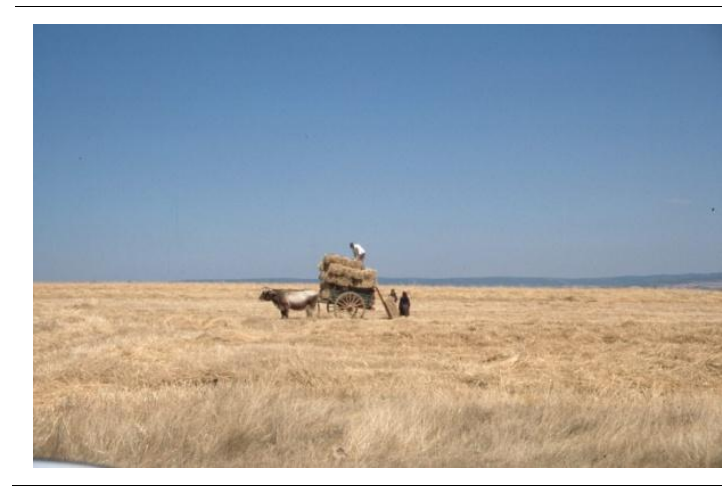
sivo pero que ha convivido durante siglos con otros de alto valor económico y paisajístico como el derivado del monte, ahora reducido a pequeñas manchas concentradas en páramos calcáreos y detríticos.

\section{Las roturaciones históricas}

Las condiciones físicas de las llanuras de la comunidad permitían la existencia de una cobertera vegetal climácica mayoritariamente forestal cuya existencia se recoge en tópicos como el de la existencia de un tupido bosque que la famosa ardilla de Estrabón podía recorrer sin tocar tierra. La existencia de tal bosque no está probada y, más bien al contrario, parece que ya a finales del neolítico se había iniciado un proceso de deforestación puntual vinculado a los procesos de rozas para preparar tierras para la agricultura, así como a la presión de los rumiantes, lo que habría generado la aparición de áreas de praderas y cobertera herbácea sobre un 15 o $20 \%$ de la superficie de las llanuras (BLANCO, 2003: 78-82). La cobertera forestal sigue siendo predominante hasta los procesos de repoblación medieval; sin embargo la presión humana y animal sobre estos recursos, a través del pastoreo, roturación y transformación de montes en tierras agrícolas y uso para madera y leñas... provoca que ya en la Alta Edad Media existieran "importantes es- 
pacios abiertos, los cuales van a ser más frecuentes que los de monte arbolado denso" (BLANCO, 2003: 418).

Como señala Blanco Abril, de forma lenta pero constante, aunque con distintos ritmos entre los siglos XIV y XIX, la presión derivada del crecimiento demográfico y las exigencias de la ganadería, con los consiguientes privilegios de la Mesta, van acentuando una situación de práctica deforestación de las áreas de llanura, reduciendo los espacios forestales a las áreas de montaña.

Ya en el siglo XIX, este proceso culmina con las desamortizaciones de bienes de propios y comunales que constituyeron, en palabras de Sánchez Zurro "...el último eslabón de las roturas seculares ilegales o amparadas por los poderes públicos" (SÁNCHEZ, 1987: 28). La generalizada deforestación de las llanuras castellanas es ya un hecho constatable a través de las opiniones de los viajeros, en los que provocaba preocupación y se asociaba a una imagen de pobreza:

"los que desnudan de esta manera sus bosques garantizan a sus hijos escasez de madera y agua, escaseces que son las dos maldiciones gemelas de la España Central' (FORD, en BLÁZQUEZ, 2010)

"A lo lejos, la tierra se asemeja al campesino español. Desnuda como él, se exhibe al sol en su capa agujereada de cizaña. Es silenciosa como él: ni un canto de pájaro, ni un murmullo de arroyuelos, ni de follaje. Sobria como él, sólo el rocío la fertiliza. Independiente como él, ni hoyos, ni empalizadas: la igualdad está grabada en su faz" (QUINET, en BLÁZQUEZ, 2010)

"La ausencia general de árboles expone estas amplias y descubiertas llanuras a la rabia y la violencia de los elementos; casas de adobe sumamente pobres, esparcidas aquí y allí con la extensión desolada, dando un lamentable refugio a la población, pobre, orgullosa e ignorante" (FORD, en BLÁZQUEZ, 2010).

Igualmente, para los estudiosos y pensadores españoles, especialmente para los que siguen las ideas regeneracionistas, la pérdida de masa forestal constituye, aplicando un criterio de rentabilidad económica de las producciones, una absoluta barbaridad:

"A esto nos han llevado esas roturaciones bestiales; esas ansias de sembrar trigo precisamente donde estaban los montes, mientras que sobre tierras calizas tres veces peores que éstas, pero que no se han roturado nunca, viven y prosperan las espléndidas razas de Durham y del 
Yorkshire que llenan de oro el bolsillo de sus dueños" (SENADOR, 1920: 166).

"Desgraciado, pues, de aquel lugar de secano donde sólo se da el trigo, como sucede en toda la llanura, porque allí la escasez no es pobreza europea, es miseria asiática, jes hambre de cipayos! (SENADOR, 1920: 233).

Las llanuras centrales de la cuenca del Duero se han convertido en espacios de producción agrícola y ganadera en las que los pocos espacios de monte, bajo y ralo en su mayoría, están asociados a las grandes fincas surgidas de la desamortizaciones y a algunas riberas, y en las que la horizontalidad de los campos sólo se ve rota por la aparición de algunos

Figura 4. Redistribución parcelaria por efecto de la Concentración. André Humbert

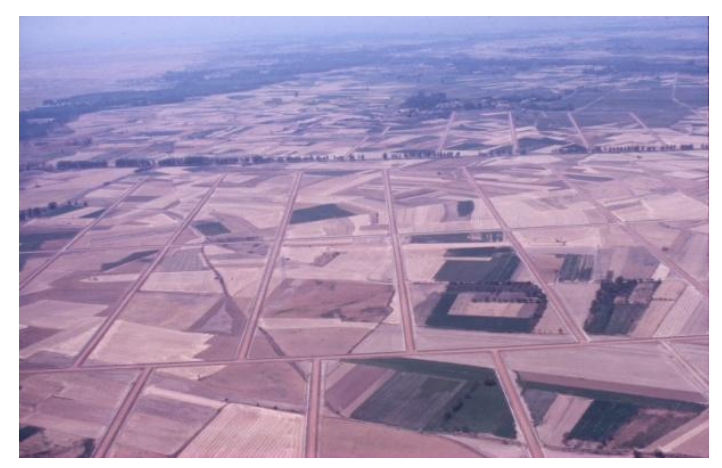
árboles y arbustos situados en las lindes de las parcelas tradicionales que acabarán desapareciendo con las reformas técnicas de la segunda mitad del siglo XX, especialmente la Concentración Parcelaria.

Figura 5. Llanuras de Valle del Esgueva y Tierra de Campos. M. Alario

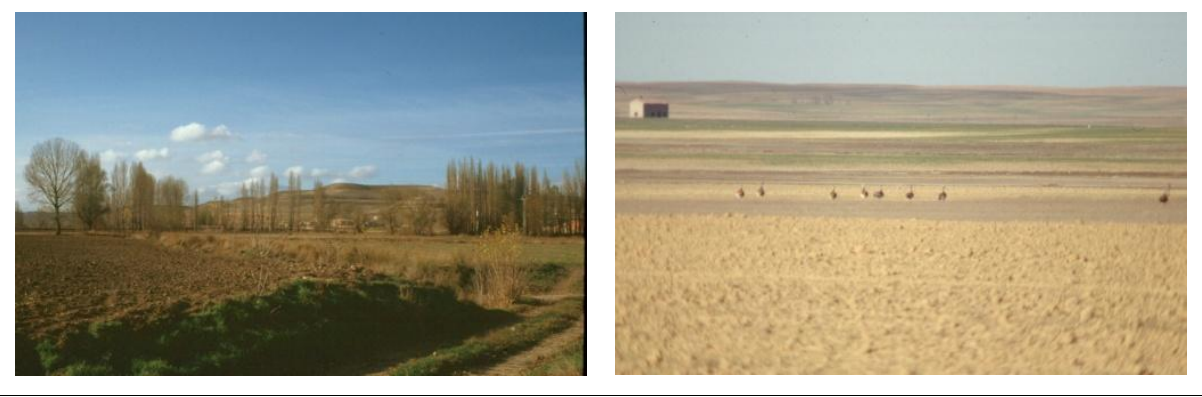

Se genera un idea de incompatibilidad entre agricultura y existencia de árboles que hace hablar a algunos autores de "odio al árbol" por parte de los agricultores. En paralelo se va conformando la imagen de las llanuras castellanas como "granero de España", producto del fuerte proceso de especialización productiva que, iniciado en el siglo XIX, se consolida en la segunda mitad del siglo XX. 


\section{PROCESOS DE ESPECIALIZACIÓN PRODUCTIVA Y REDUCCIÓN DE LA DIVERSIDAD PAISAJÍSTICA: LOS EJEMPLOS DE CAMPOS Y CERRATOS}

El proceso histórico de ocupación de las llanuras de Castilla se basa, como ya se ha dicho, en la ocupación, roturación y puesta en cultivo de las áreas de monte. La diferente aptitud de los suelos marca la intensidad de este proceso ya que, como señala Sánchez Zurro, "los suelos sueltos del lecho de los grandes valles fueron los más apropiados para tierras labrantías, junto con los de las Campiñas de Tierra de Campos, la Tierra del Pan zamorana y los de la Armuña y Campo de Peñaranda ...todos ellos apropiados para el cultivo de panes....Los arcillosos, y con frecuencia esqueléticos, de los páramos pontienses fueros considerados, durante siglos, como tierras frías y desoladas, apropiadas para el cultivo de la avena y el centeno" (SÁNCHEZ, 1987: 14)

Las limitaciones de los intercambios, reducidos a los mercados de villa y con un ámbito muy local, exigían el mantenimiento de unas producciones diversificadas que permitieran abastecer las necesidades básicas de la población en una economía en gran medida de susbsistencia. Así, como señala Sánchez Zurro, los paisajes agrarios presentaban mucha mayor variedad que en la actualidad, con importante presencia de viñedos, frutales, huertos, prados y hazas de producción de lino y cáñamo, que no ocultaban, sin embargo, la preeminencia del cereal como elemento básico de la alimentación.

La expansión del ganado lanar desde el siglo XII y las franquicias y privilegios reales al comercio de la lana generaron una actividad floreciente en toda Castilla pero también supusieron una cierta alteración de la organización agraria anterior pues, como señala Sánchez Zurro (1987: 19), “... a lo largo del los siglos XIV y XV, la oveja entró en competencia con el arado...múltiples conflictos estallaron entre campesinos y pastores".

Fruto de la necesidad de solucionar estos conflictos aparece lo que será una de las señas de identidad del paisaje de las llanuras cerealistas de Castilla hasta avanzado el siglo XX: la organización de los campos en hojas de cultivo. En efecto, las ordenanzas publicadas desde el S.XV van regulando la distribución de las tierras en producción y de los espacios en barbecho, de forma que se permita el paso de un ganado cada vez más importante en las llanuras castellanas y se facilite el pasto. Así, en función de la calidad y feracidad de los suelos se establecen rotaciones de año y vez, al tercio o al cuarto, separando físicamente el cultivo y el barbecho en hojas dentro de cada pago en el conjunto del término "...pero panes y cañas siempre aparecían separados con la finalidad de no entorpecer el paso y el pastoreo del 
ganado" (SÁNCHEZ, 1987: 22). División regulada en hojas que no afecta al resto de las producciones agrarias como el viñedo, los frutales, los linares o las huertas, que aparecían en pagos propios generalmente situados en áreas más cercanas a los núcleos de población o en lugares con condiciones físicas específicas, como los viñedos asociados a los suelos guijarrosos y sueltos.

Todos estos elementos y su organización física en el espacio van a marcar los paisajes agrarios tradicionales de las llanuras castellanas de forma que “...El terrazgo productivo se organizó en torno a las aldeas y villas. Los huertos, las cortinas y herrenales, generalmente cercados, de aprovechamiento individual, destinados a hortalizas, lino o herrén, se localizaban en torno al núcleo compacto de caserío de mampuesto o tapial. Mas allá los pagos de sembradura divididos en hojas; diferenciados de éstos, y limitados frecuentemente por árboles frutales, se localizaban los viñedos; las dehesa boyal y el corral del concejo; los prados de corta y diente; los montes y baldíos de propios y comunales.... Campos abiertos pero más boscosos que en nuestro siglo. No sólo los montes ocupaban mayor extensión sino que los viñedos, con el cortejo de árboles frutales que les acompañaban, y las zarzas entre caminos, hacían de Castilla y León una región de paisajes más variados" (SÁNCHEZ, 1987: 26).

\section{Hacia la especialización agrícola}

La preeminencia del modelo burgués y sus principios capitalistas van a provocar la desaparición de los modelos productivos tradicionales y la consolidación de unas nuevas estructuras productivas que priman las producciones agrícolas frente a las ganaderas. Como señala Sánchez Zurro, la eliminación de los privilegios de la Mesta, las sucesivas desamortizaciones y sus consecuencias en cuanto a transformación de antiguas áreas de monte en espacios de cultivo, van a provocar una significativa reducción del valor de la producción ganadera en la región en un $20 \%$ y de la carga ganadera en casi un 40\% (SÁNCHEZ, 1987: 29), como consecuencia de lo cual Castilla y León, y especialmente sus llanuras, van a iniciar el camino que las convertirá en espacios agrarios especializados en la producción de cereal, básicamente trigo y viñedo, que derivará, junto con el mantenimiento del ganado lanar como complemento productivo, en las señas de identidad de sus paisajes.

La construcción del Canal de Castilla en 1849 y la terminación del ferrocarril Alar-Santander en 1866, van a suponer una gran mejora en la accesibilidad que facilitará la exportación de trigos y harinas generando la imagen de la Castilla "granero de España" que se va a mantener en el imaginario tradicional hasta la actualidad y que se repite en publicaciones y obras variadas, 
incluso en himnos como el Palencia que se inicia con un "Dios te salve Palencia querida, Dios te salve granero de España...".

Resultado del incremento de la demanda interior, debido al crecimiento de la población regional, y exterior, por las exportaciones a otros mercados, la superficie de producción cerealista crece hasta convertirse en dominante en el último tercio del siglo XIX, suponiendo en algunas comarcas más del $80 \%$ de la superficie cultivada (Tierra de Campos, Torozos, Tierra del Pan, Cerratos.).

El otro gran elemento del paisaje agrario de las llanuras de Castilla es el viñedo. Producto de gran tradición conocido desde los romanos, alcanza su máximo esplendor en los siglos XVIII y XIX, vinculado tanto al consumo local y de autoconsumo, en Campos y Torozos, como a los mercados de las ciudades del norte de España en los la Tierra de Medina, Cigales y la Ribera. $\mathrm{Su}$ gran capacidad de producción y su enorme demanda y buen precio lo convirtieron en uno de los productos agrarios fundamentales en la región:

“...Para un vecindario de tres mil quinientas almas, poco más o menos, se recolectaban anualmente doscientos mil cántaros de vino; que, vendidos en el mismo pueblo a los tragineros al promedio de dos pesetas cuando más barato, importaban cuatrocientas mil pesetas, sin contar los demás aprovechamientos del viñedo para leñas, pastos, caza, cultivo de frutales, mantenimiento de colmenas, y otros semejantes" (SENADOR, 1920: 104)

Además, formaba parte fundamental de la dieta hasta el punto de que constituía parte establecida del jornal de los trabajadores y “...especialmente en la época de recolección de las cosechas, un propietario de tres pares de labranza necesita invertir en vino para sus obreros poco menos de quinientas pesetas...Claro está que el alcohol es un alimento venenoso, pero el obrero no lo cree; y reclama su vino antes que su salario..." (SENADOR, 1920: 114115)

La crisis de la filoxera, que afectó a los viñedos castellanos en la última década del siglo XIX, así como el cierre de los mercados franceses, cuya producción ya se había recuperado, y la competencia de los vinos manchegos, terminaron de hundir el viñedo regional que, en la provincia de Valladolid, por ejemplo, se redujo en casi un 60\% (MOLINERO, 1988: 16-18). El viñedo se mantiene, sin embargo, ya que, a pesar de lo señalado, seguía considerándose un cultivo productivo, que ocupaba la mano de obra disponible y ofrecía la posibilidad de cubrir una parte importante de la dieta. Sin embargo, su reducción superficial permitió el reforzamiento de la vocación cerea- 
lista de las llanuras y a ella se dedicaron, incluso, algunas tierras de laderas arenosas poco propicias a esta producción.

Complementario pero no por ello menos importante era el ganado de renta, especialmente el lanar que, mediante el aprovechamiento regulado de pastos y rastrojeras, aportaba unas significativas rentas con un coste muy bajo. Los censos ganaderos se mantienen muy elevados hasta mediados del siglo XX, superando las 320.000 cabezas en el caso de la Tierra de Campos, de las que se obtenía, funda-

Figura 6. Campos castellanos. Benjamín Palencia 1959

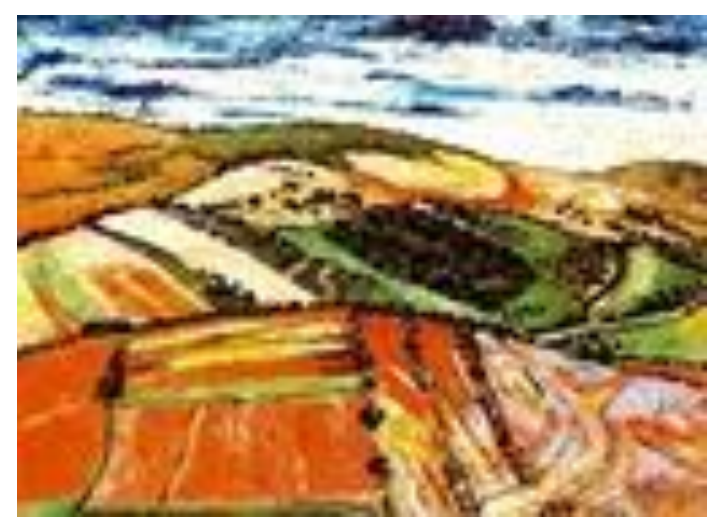
mentalmente leche, carne y lana (PEÑA, 1987: 123-125).

Sin embargo, la crisis finisecular que afectó a los mercados del cereal, reduciendo su precio, menguó las ya de por sí exiguas rentas de los pequeños agricultores cerealistas, impulsando las primeras grandes salidas de población agraria regional, que originará una de las características fundamentales de estos espacios: la escasez de población y el abandono, dando pie a esa imagen de la Castilla en escombros, reflejada en la obra de Julio Senador.

Desde un punto de vista paisajístico, sin embargo, la monotonía del cereal se verá aún alterada de vez en cuando por pies de árboles frutales y arbustos de setos vivos que conforman las lindes de una parcelario fragmentado y tradicional, así como por el mantenimiento de algunas viñas dispersas en todo el territorio, acompañadas de sus correspondientes barrios de Figura 7. Alrededores de Valladolid. Martín Galindo años 50

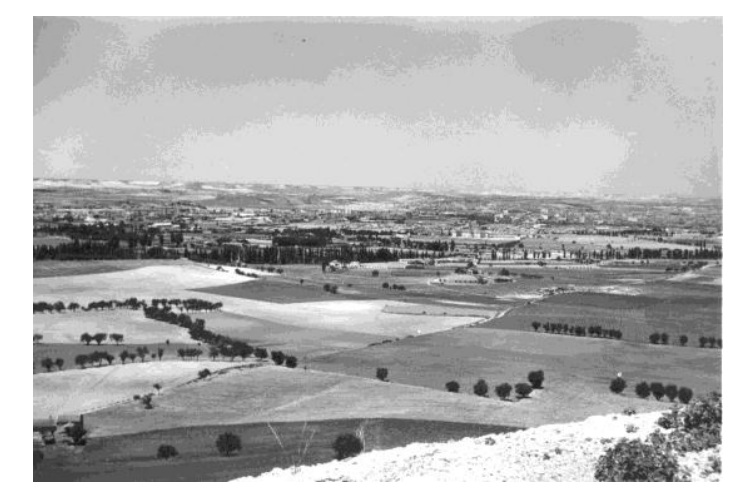
bodegas, omnipresentes en todos los pueblos castellanos. Un paisaje, en fin, que mantiene una cierta diversidad aunque ya marcado por la especialización cerealista que dará un 
salto cuantitativo y cualitativo con los cambios provocados por la modernización agraria de la segunda mitad del siglo XX.

\section{Monoespecialización productiva y simplificación del paisaje.}

En los inicios de la segunda mitad del siglo XX, las llanuras centrales de Castilla y León eran espacios de clara especialización agrícola y cerealista. Así, en Tierra de Campos más del $91 \%$ de la superficie productiva estaba catalogada como tierra de labor, y más de un $80 \%$ de la superficie cultivada se dedicaba a la producción de trigo. El proceso de integración de estos espacios en la economía capitalista determinaba la primacía del mercado como elemento rector de las producciones, si bien, como señala Peña Sánchez, la mayor parte de las pequeñas explotaciones "seguía teniendo como una de las finalidades prioritarias asegurar la subsistencia de la familia campesina. No la única, por supuesto, ya que el labrador ya no podía quedar al margen del circuito comercial; pero, si aseguraba la subsistencia, se había cumplido una parte fundamental del objetivo" (PEÑA, 1987: 101-102).

Como señala Peña Sánchez, las exigencias derivadas de unas duras condiciones físicas y la utilización de técnicas de cultivo rudimentarias imponían el mantenimiento de rotaciones de cultivo mayoritariamente de año y vez que, hasta los años 60 del siglo pasado, seguía respetando voluntariamente el sistema de organización en hojas de cultivo. Los paisajes agrarios estaban marcados pues por la especialización cerealista organizada en dos grandes hojas que separaban las tierras en producción de las tierras en descanso. Salpicando algunas de las parcelas en barbecho, cultivos de leguminosas (lentejas y garbanzos generalmente), orientadas fundamentalmente al autoconsumo. Las ovejas pastando sobre las hojas de barbecho y las pequeñas parcelas de viñedo, con destino al autoconsumo y los mercados locales, ocupando en las tierras más arenosas y sueltas, completaban esta imagen de los paisajes agrarios de las llanuras.

La plena integración en el modelo capitalista moderno se inicia en la segunda mitad del siglo XX y culmina en la década de los 70 con una actividad agraria plenamente dependiente del mercado, tanto para producir como para vender, un alto nivel de tecnificación y la consiguiente reducción de mano de obra y población agraria necesaria. La desarticulación del modelo tradicional de producción, provocada por la salida masiva de personas hacia los más atractivos mercados de trabajo urbano-industriales, acabará transformando completamente la dinámica económica de las llanuras castellano-leonesas. Resultado de dicho proceso encontramos una agricultura monoespecializada en la que las producciones no mercantiles desaparecen, y unos paisajes agrarios marcados por la monotonía productiva y el abandono poblacional. 
Desde la década de los años 50, y especialmente en los 60, el desarrollo industrial del país exige el concurso de una gran número de trabajadores que van a salir, fundamentalmente, de los espacios agrarios y, sobre todo, de aquellos cuyas condiciones económicas y sociales eran más precarias, como ocurría con los espacios rurales de Castilla y León. Así, en las llanuras de la Tierra de Campos se pierde la mitad de la población en tan sólo 20 años, entre 1955 y 1975 , y procesos similares afectan a las comarcas de Torozos y el Cerrato.

La salida de jornaleros, primero, y pastores y pequeños propietarios después, determina una avalancha de cambios en las formas de producción, la más importante de las cuales es la tecnificación de las labores. Los tractores entran de lleno en las explotaciones y desaparece el ganado de labor. El escaso abonado orgánico aportado por esta ganadería y por la palomina en las llanuras centrales, se sustituye por abono químico que incrementa la producción y reduce los tiempos de descanso necesario de las tierras de cultivo hasta un escaso $30 \%$ de barbecho en 1985. Las explotaciones incrementan su tamaño y especializan sus producciones. (CABO, 1987: 55).

Todas estas transformaciones serán apoyadas por las administraciones públicas mediante planes de mejora y modernización de las estructuras agrarias. De entre estas reformas hay que destacar aquellas que introducen significativas variaciones de paisaje como son la los planes de transformación en regadío y la concentración parcelaria.

Figura 8. Cerrato Palentino. Parcelario Figura 9. Parcelario Tierra de Campos 2011 Palentina. 2011
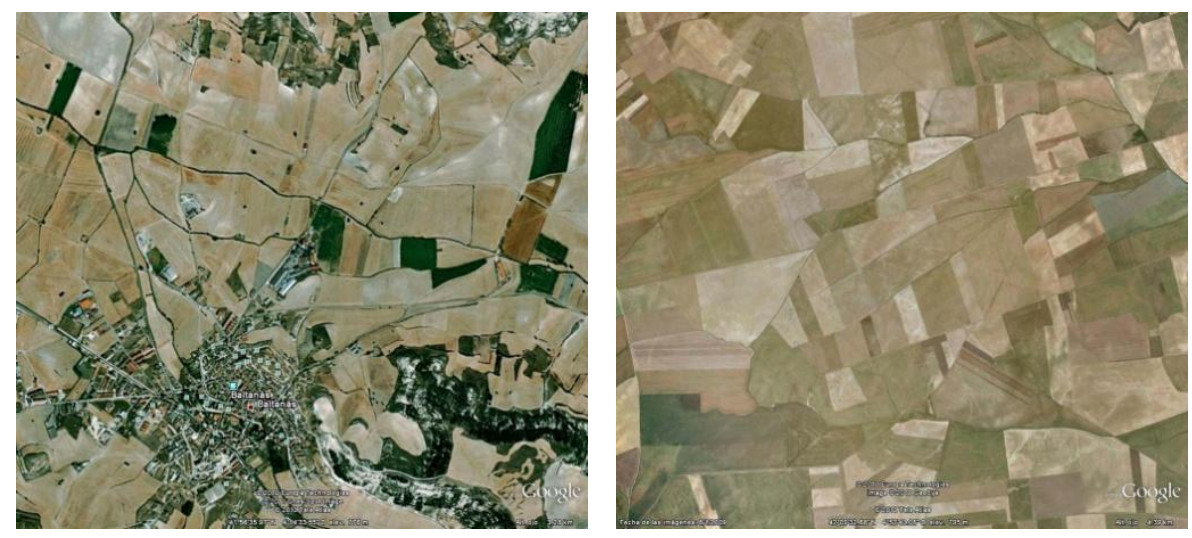

La transformación en regadío, aunque sólo afecta a una parte de estos espacios, supone unos cambios de tal magnitud que genera nuevo paisajes 
agrarios, analizados en otro capítulo de esta publicación. Vamos pues a centrarnos en la gran reforma técnica que se aplica en la práctica totalidad de las llanuras castellano-leonesas: la concentración parcelaria.

Figura 10. Valderas (León) antes y después de la concentración parcelaria. Daniel Herrero 2010

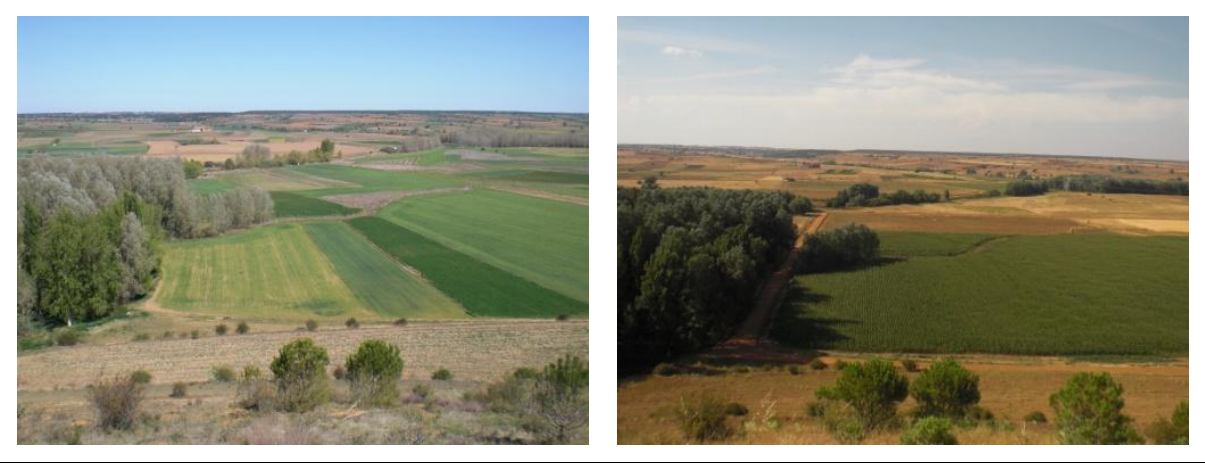

Figura 11. Tierra de Campos Valladolid.

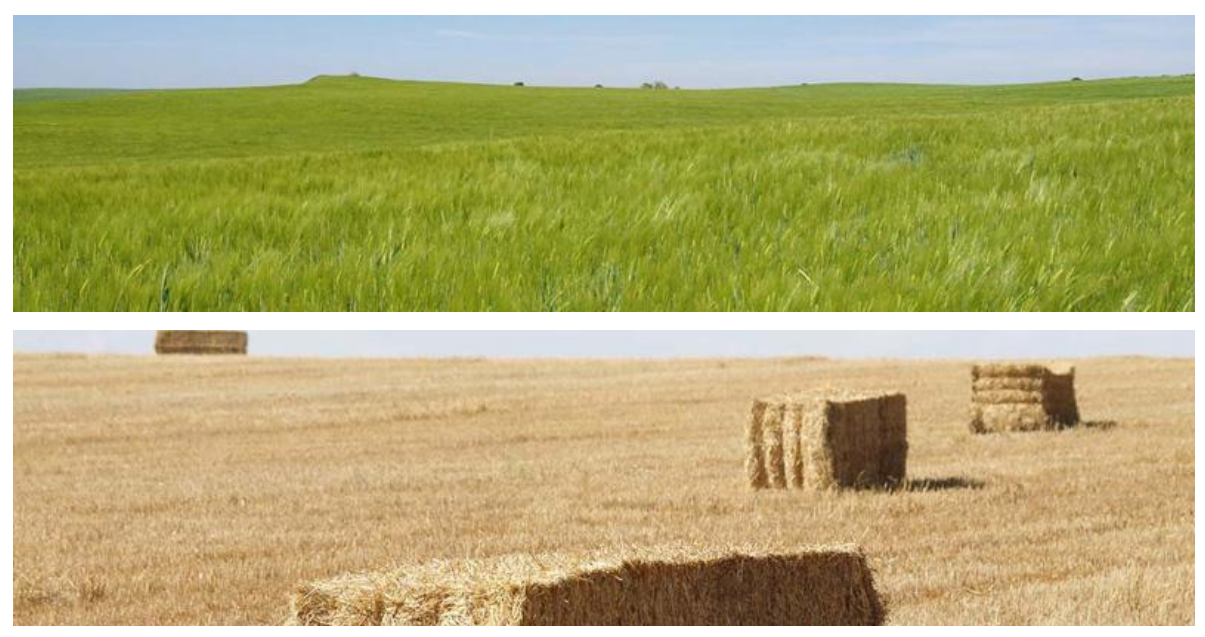

Fuente: Tierra de Campos Zona Norte de Valladolid. http://www.tierradecampos.com/ paisajes_y_naturaleza_en_tierra_de_campos.php consultado enero 2011

Las llanuras cerealistas del centro del país fueron las primeras que en las que se abordó, de forma experimental, la realización de la concentración parcelaria, en aplicación de la ley experimental de 1952. De hecho tres de las cinco zonas seleccionadas corresponden a estas áreas de las llanuras cerealista de la región (Peñaflor de Hornija, Torrelobatón y Cantalapiedra). Las sucesivas leyes de 1954 y 1962 consolidan la aplicación de esta reforma es- 
pecialmente en las tierras agrícolas y, especialmente, en las de producción de cereal que, por su homogeneidad y facilidad técnica en la aplicación de la norma, eran las que mejor se prestaban a la obtención de rápidos y óptimos resultados. Así, al finalizar la década de los años 80 las comarcas de las llanuras de la cuenca habían superado el umbral del $75 \%$ de su superficie concentrada sobre concentrable (ALARIO, 1991: 127).

El predominio de los pequeños propietarios en la región hace que el tamaño medio de lo aportado al proceso de concentración parcelaria sea reducido, con poco más de 5 ha por propietario, sin embargo los resultados de su aplicación pueden ser considerados como muy buenos. El índice de reducción conseguido, entre 5 y 8 en todas las áreas de este análisis, supone que las entre 10 y 15 parcelas aportadas por cada propietario se convierten en menos de 2 después de la concentración. Consecuentemente su tamaño aumenta de forma significativa y, por ejemplo en la Tierra de Campos vallisoletana, de una media de 0,65 ha de la parcela inicial se alcanzan fincas concentradas con una superficie media de 4,69 ha.; en el Cerrato palentino se pasa de 0,53 a 3,31 ha.

Aunque es evidente que los problemas derivados de la realización de la concentración parcelaria por propietarios individuales minimizaron su impacto positivo en la conformación de un parcelario moderno y racional, adaptado a las nuevas técnicas de producción, lo cierto es que la concentración puso las bases de una profunda reestructuración que, por la vía de las adquisiciones, uniones de parcelas pertenecientes a la propiedad familiar (que se había tendido a entregar junta en buena parte de las concentraciones parcelarias de la región) y tenencia indirecta, ha llegado a conformar una estructura parcelaria totalmente nueva y distinta a la tradicional.

Lo primero que llama la atención, morfológicamente hablando, de esta nueva estructura parcelaria es el orden y la geometría de sus teselas, con predominio de formas regulares, rectangulares o cuadradas en lo posible, alineadas en torno a los caminos que les dan servicio de acceso. En segundo lugar, es llamativa la práctica desaparición de las lindes, ya que la mecanización y la regularidad de las formas facilitan un mejor y mayor aprovechamiento de toda la superficie productiva al permitir una mejor maniobrabilidad de la maquinaria. El nuevo trazado de las parcelas concentradas cuyos límites se señalan sólo con mojones elimina los setos vivos y las discontinuidades y rugosidades del terreno entre parcelas, que desaparecen como parte de la adecuación de las nuevas fincas. Todo ello, unido a la homogeneidad de los aprovechamientos conforma unos paisajes en los que, en una vista horizontal, es difícil percibir el límite de las fincas, generando esa imagen de "mar de cereal" que se ha convertido en la de los secanos castellanos. 


\section{LA VARIEDAD DE LOS SECANOS CEREALISTAS.}

A pesar de que los procesos básicos, señalados hasta aquí, son sin duda comunes a todo el conjunto de los secanos cerealistas del Duero, la diversidad de condiciones físicas, de estructuras productivas y, por supuesto, de grado en la integración económica de cada comarca, inducen la existencia de significativas diferencias que nos permiten hablar de varios tipos de paisaje.

\section{Las llanuras de Tierra de Campos como paradigma de los secanos cerealistas}

Constituyen sin duda el paradigma de estos paisajes. Es en estas áreas de llanuras, que se extienden por las campiñas sedimentarias de las provincias de Palencia, Valladolid y Zamora, donde son más perceptibles las características de las que hemos hablado hasta aquí: deforestación prácticamente absoluta, monoespecialización productiva en torno a la cebada y el trigo, explotaciones que, por mor de la modernización y mecanización, han ido incrementando su tamaño hasta superar sobradamente los dos centenares de hectáreas y que se manifiestan en el espacio en forma de grandes parcelas marcadas por la regularidad y la monotonía de aprovechamientos. Todo ello, articulado en torno a una densa red de poblamiento fuertemente aquejado por la despoblación, el envejecimiento y la ruina física.

Sin embargo este "mar de cereal", imagen de la Castilla granero de España, también se ha visto afectada por procesos de cambio radical en parte de sus espacios iniciales. Los planes de regadío ejecutados por la administración pública en la segunda mitad del siglo XX, coincidiendo con los procesos de integración de mercado y desarrollo de una agricultura productivista, han generado nuevos paisajes que, si bien de orientación similar, introducen mayor diversificación productiva y producen nueva formas espaciales a veces muy contrastadas. Así, como ejemplo de lo que significan paisajísticamente los planes de regadío de estas comarcas, en medio de la Tierra de Campos Palentina aparece, como una anomalía verde y ganadera, la Nava de Campos, con sus regulares parcelas de alfalfa y cereal, producto de la desecación y colonización efectuada en los años 50 y 60 .

La situación en este espacio de las capitales de Valladolid y Palencia provoca, igualmente, una fuerte alteración paisajística vinculada a los procesos de periurbanización y difusión económica a lo largo de los ejes de comunicación, que introducen funciones, dinámicas y paisajes nuevos.

\section{Las cuencas menores de Bureba y Almazán}

Junto a las grandes comarcas, por extensión superficial, de los espacios 
centrales de las llanuras, aparecen un conjunto de pequeñas cuencas y campiñas marginales como la de La Bureba, Riaza, Roa, Almazán, o la depresión de Ciudad Rodrigo. Todas comparten la importante presencia de los cereales como cultivo fundamental, pero sus especificidades, bien por condiciones orográficas o diversidad productiva, las diferencian nítidamente de las llanuras de Campos. Tomemos con ejemplo dos de las más significativas: La Buera y la cuenca de Almazán.

La condición de cuencas periféricas de pequeño tamaño y sus peculiares condiciones físicas introducen algunas diferencias significativas con respecto a las llanuras centrales de la cuenca. La comarca de Almazán presenta un mayor volumen de superficie forestal de pinares, así como pastos asociados a las áreas más elevadas que, en conjunto, suponen más de la mitad de la superficie. En el resto, la superficie arable, son los campos de cultivos herbáceos los dominantes con paisajes similares a las llanuras de Campos, si bien las parcelas son significativamente de menor tamaño, en relación con las condiciones orográficas y de estructuras agrarias dominantes.

La comarca de La Bureba, utilizada como ejemplo tradicional de comarca natural, aparece situada en el noreste de la provincia de Burgos, vertiente al Ebro, y bien delimitada por un cíngulo montañoso compuesto por la Mesa de Oña, los Montes Obarenes y de Oca con un acceso natural a través del desfiladero de Pancorbo. Está asociada a la imagen de feracidad fundamentada en las mejores condiciones climáticas y edáficas, producto de su relleno sedimentario terciario. Es el área triguera por excelencia de las llanuras castellanas, con una producción especialmente destinada al trigo panificable, acompañado de cebada maltesa. La elevada productividad del cultivo del cereal dominante justifica el predominio de la pequeña explotación, ligeramente menor a la de otras comarcas, que se traduce en un menor tamaño de las parcelas respecto a otras llanuras de la región. Las dificultades derivadas de este hecho han llevado a los agricultores de la comarca a asociarse en cooperativas como la Bureba-Ebro.

La presencia de ganadería es escasa en la llanura y generalmente, está vinculada a explotaciones especializadas, lo que condiciona su reducida huella espacial. El tránsito de las llanuras hacia los bordes montañosos de la cuenca de La Bureba provoca un cambio de paisaje, en el que la mayor fragmentación del terrazgo va acompañada de la presencia de superficies arboladas y la consiguiente reducción del peso de las producciones de cereal como elemento dominante. 


\section{Los Páramos del Cerrato y Torozos}

Las llanuras estructurales formadas por el recubrimiento sedimentario de materiales calizos ocupan extensas áreas en el centro-norte de la región. Los procesos generales de especialización productiva, ya analizados, marcan de forma fundamental las líneas de sus paisajes, pero las diferencias con respecto al modelo de las campiñas derivan de dos hechos de distinto carácter. Por un lado de la propia estructura física de estos espacios, en cuya organización tienen un peso fundamental los valles. Por otro, unas estructuras agrarias que se caracterizan por la presencia histórica y actual de grandes propiedades.

La importancia de los valles, que tajan las elevadas plataformas estructurales, es fundamental. En ellos se ubican la mayor parte de los núcleos de población y allí, junto a los cursos fluviales, se desarrollan las estrategias de intensificación de producciones mediante el regadío, más o menos tradicional, de bombeo desde los cursos fluviales. Por el contrario, las altas llanuras de los páramos, tanto en Torozos como en el Cerrato, constituyen el espacio del aprovechamiento cerealista y el reducto de los espacios forestales que otrora caracterizaron sus paisajes. A pesar de la aparente contradicción, no son elementos opuestos sino complementarios ya que ambos aprovechamientos forman parte de las mismas explotaciones en la mayor parte de los casos, si bien es cierto que se mantienen algunas explotaciones muy pequeñas de carácter hortícola en los valles de algunos ríos, así como algunas que se trabajan a tiempo parcial.

El segundo factor explicativo del paisaje agrario de estas comarcas, es el peso de las grandes propiedades y explotaciones. Los procesos de desamortización convirtieron grandes masas de monte, propiedad de comunes y propios, en fincas de gran tamaño en coto redondo a cuya propiedad accedieron, en un buen número de casos, personajes de la burguesía urbana. El resultado es que más de un tercio de la superficie comarcal pasó a manos de grandes explotaciones. El cambio de propiedad induce un cambio de uso, imponiéndose las producciones agrarias que relegan el monte a espacio marginal o complementario pero que introducen una cierta variedad en el paisaje aunque se trate ya sólo de algunas presencias arbóreas singulares. La escasa ganadería de la comarca está vinculada de forma importante a estas explotaciones y son también ellas las que están abanderando el desarrollo de usos no agrarios vinculados con el turismo rural (granjas-escuelas, centro de turismo...)

Allí donde el modelo de gran explotación llegó, la orientación dominante es la producción agrícola de cereal, potenciada especialmente en la segunda mitad del siglo XX cuando el desarrollo de la mecanización permitió un me- 
jor laboreo de las duras y rocosas plataformas calcáreas, de cuya exigencia se derivó la aparición de los "majanos", amontonamientos de piedras, producto de la limpieza de las parcelas, que bordean las lindes. A pesar de tratarse de explotaciones familiares, un tamaño superior a la media regional y una buena calidad técnica de las labores de concentración, se traducen en parcelas de gran tamaño y regularidad que refuerzan la monotonía de las aparentemente interminables llanuras de los páramos calcáreos.

\section{Las llanuras del sur del Duero}

En las campiñas del sur del Duero, estructuralmente similares a las del norte, las diferencias vienen, de nuevo, de la mano de dos factores, uno natural y otro estructural. El primero está relacionado con el tipo de suelos, más sueltos debido a su mayor componente arenosa que alcanza sus niveles máximos en la Tierra de Pinares vallisoletana y segoviana, con un paisaje agrario bien diferenciado del entorno. El segundo tiene que ver con la significativa presencia de grandes explotaciones que han abanderado el proceso de transformación productiva mediante el regadío de perforación, aprovechando los niveles piezométricos relativamente someros.

Figura 12. Campiñas del sur del Duero. Mezcla regadio de perforación y secano. Google Earth 2011

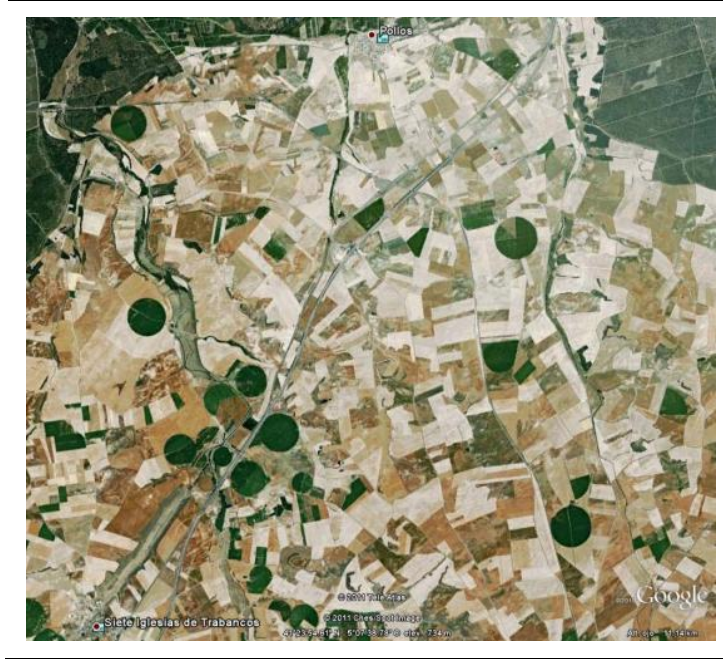

El resultado es un paisaje agrario marcado por un mosaico de cultivos, mezcla de cereales de secano con regadíos de carácter más o menos intensivo, de la mano de la expansión de la remolacha y el maíz, con presencia se masas forestales allí donde el recubrimiento arenoso es mayor. El parcelario es regular y de buen tamaño, producto de la concentración parcelaria y los procesos espontáneos de ampliación por compra para rentabilizar las inversiones en infraestructura de regadío y otras mejoras.

\section{Las llanuras detríticas}

Llanuras casi perfectas son plataformas de mayor altitud, entre los $750 \mathrm{y}$ los 1100 metros, cubiertas de canturral suelto, arrastrado por los ríos en el 
Pleistoceno y Cuaternario (CASCOS, 1987, 23), que se extienden desde los piedemontes detríticos del borde noroccidental de las llanuras regionales, pasando por los depósitos de piedemonte de las llanuras de Guardo-Saldaña, hasta los páramos detríticos de León. Sus suelos ácidos y sueltos les han hecho tradicionalmente poco aptos para una producción agrícola de alto rendimiento y, en secano, han sido históricamente tierras centeneras ganadas, mediante roturaciones, al bosque primigenio de roble. La segunda mitad del siglo XX es, al igual que en resto de las llanuras castellanas, la época de la modernización productiva de la mano de la especialización, la pérdida de la diversidad y la desaparición de la importante ganadería complementaria que, en el mejor de los casos, se transformó en ganadería intensiva de leche. Todo con el objeto de promover una especialización cerealista en unos suelos poco productivos. Escaso valor agrícola que justifica el mantenimiento de una significativa cobertera forestal en forma de montes más o menos degradados de robles y pinos. El cultivo de cereal, con ser dominante en las áreas sembradas, no conforma paisajes muy marcados debido a la mezcla de usos y las rupturas que introducen los espacios forestales y regados, que pueden llegar a conformar paisajes completamente específicos y diferentes a los descritos, que se salen de los modelos analizados en este artículo.

\section{DISFUNCIONALIDAD Y ELIMINACIÓN DE ELEMENTOS TRADICIONALES DEL PAISAJE}

Las transformaciones económicas y sociales de los años 60 y la imposición de una agricultura productivista monoespecializada ha provocado, como consecuencia directa, la disfuncionalidad de algunos elementos que conformaban los paisajes tradicionales y su abandono e incluso desaparición física o, en el mejor de los casos, su recuperación para nuevas funciones.

\section{Una red de poblamiento heredada y marcada por la despoblación}

Como señala Benito Martín, la red de poblamiento con la que hoy contamos en Castilla y León es producto fundamentalmente de los procesos de repoblación medievales acaecidos entre los siglo IX y XI en el norte del Duero y en los dos siglos posteriores en el área del sur. Partiendo de la existencia de núcleos de origen anterior, será en ese momento cuando la reocupación de estas tierras relance su explotación. Por lo que se refiere a los modelos de ocupación Benito Martín diferencia tres tipos: civitas, castrum y villae. Los primeros serían núcleos con algún tipo de poder institucional, son pocos, ubicados en lugares estratégicos y muchos de ellos constituyen la trama básica de la estructura urbana regional (Astorga, Zamora, Aranda, Salamanca, Palencia...). Los castrum constituyen núcleos con una función defensiva y, en consonancia, suelen estar amurallados. Muchos de ellos surgen 
a partir de la ocupación de núcleos anteriores y su ubicación está muy vinculada a los valles de los ríos y en las cuestas de enlace entre páramo y llanuras. Las villae son las células básicas de la red de poblamiento que permiten la ocupación del territorio en un momento de importante crecimiento demográfico. (BENITO, 2005).

En este proceso de ocupación el área de las llanuras sedimentarias de la cuenca del Duero adquiere una importancia fundamental ya que, como señala Benito Martín: "Esta zona, de evidentes aptitudes para una economía agrícola medieval, ejerció durante los tiempos medievales un gran poder de atracción, constituyéndose en el centro neurálgico de la meseta. No en vano, tras la división del reino por Alfonso VII (1157-1230), en los conflictos fronterizos entre sus sucesores fue la zona más disputada y problemática de la frontera... Desde la división de los reinos por Alfonso VII en 1157 hasta su definitiva unificación en 1230 por Fernando III, la frontera entre ambos fue teatro de avatares y conflictos, pero sobre todo de un intenso proceso de creación urbana por parte de los monarcas de ambos reinos, aunque más del leonés, cuyo resultado fue una densa red de villas reales en Tierra de Campos y en los principales cauces fluviales leoneses, sobre todo el Esla.". (BENITO, 2005: 62)

Los siglos XI al XIII constituyen un período de consolidación y reorganización de los asentamientos altomedievales del norte del Duero, algunos de los cuales desaparecen y pasan a convertirse en despoblados por procesos de concentración demográfica en algunas de las villas mejor situadas para el control económico del territorio, lo que genera, junto con algunas otras desapariciones provocadas por factores más puntuales como catástrofes naturales o epidemias, un buen número de despoblados hasta el siglo XV (REGLERO, 1998). Mientras, en el sur del Duero, se produce la ocupación estructurada del territorio de forma muy rápida a través, fundamentalmente, del sistema de villa y tierra que va a consolidar un menor número de núcleos pero de mayor tamaño y poder. (BENITO, 2005).

Sobre esta red básicamente medieval se van a producir períodos de fuerte crecimiento demográfico como los acaecidos entre los siglos XIV y XVI, y desde fines del XVII a la crisis finisecular del XIX, pero también grandes crisis demográficas que provocan la aparición de un importante número de despoblados como la del siglo XVII. Pero sin duda la principal crisis, en el sentido de ruptura, del poblamiento rural de las llanuras de Castilla, deriva de las transformaciones socioeconómicas producidas en la segunda mitad del siglo XX.

En efecto, el enorme éxodo rural que afecta a la población rural de Casti- 
lla y León provoca una fuerte reestructuración administrativa de los municipios de Castilla y León, con una pérdida de 321 municipios anexionados por otros de mayor tamaño entre 1960 y 1981. Los núcleos que quedan deshabitados alcanzan los 144, afectando en mayor medida a las áreas de montaña y piedemonte (LÓPEZ et AL., 1985: 33-34). En los sectores de llanura que nos ocupan los problemas vienen más por la pérdida de masa demográfica y el envejecimiento de la población residente, con la consiguiente pérdida de servicios y las mayores dificultades de acceso a algunos servicios básicos como la educación o la sanidad.

Figura 13. Unidades de poblamiento por tamaño. Castilla y León 2008

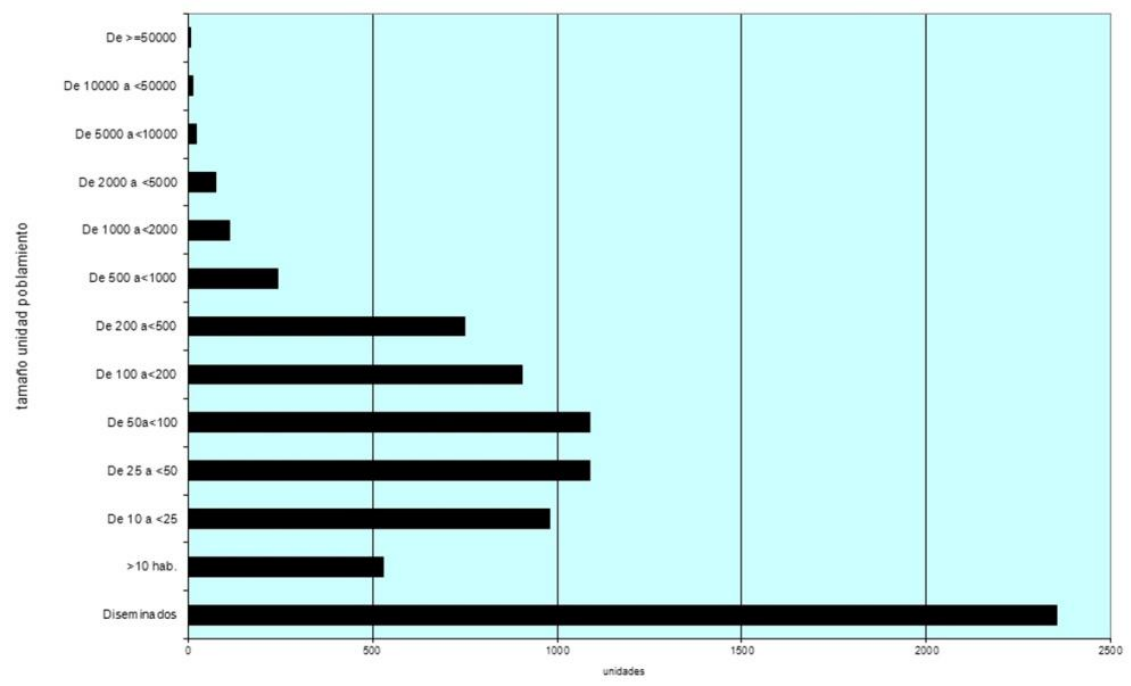

FUENTE: INE, Nomenclator 2008. Elaboración M. Alario

Según el nomenclátor de 2008, más de 5300 núcleos de población de Castilla y León tienen menos de 500 habitantes y más de 3000 figuran con menos de 100 personas registradas. Nos encontramos, ahora, con una red de poblamiento enorme, constituida por casi 6000 núcleos de población y más de 2000 diseminados, para una población que supera apenas los 2,5 millones de personas, que se concentran de forma fundamental en los núcleos urbanos y periurbanos del sistema. O lo que es lo mismo, una red de poblamiento marcada por una fuerte disfuncionalidad ya que deriva de unos contextos económicos y sociales muy diferentes a los actuales en los que la ocupación, aprovechamiento y control del espacio rural requerían un gran número de personas y cuya capacidad de controlar el espacio era reducida debido al escaso desarrollo técnico y al predomino de medios de transporte tradicionales. 
Estos datos constituyen el reflejo de un proceso imparable de regresión demográfica iniciado en la segunda mitad del siglo $\mathrm{XX}$ y que aún hoy continúa, tanto por salida de la población como por dinámica natural regresiva. Efectivamente, a la salida de población joven en busca de mejores opciones laborales y condiciones de vida, se suma ahora en muchos de nuestros pueblos la

Figura 14. Boada (Palencia). Martín Galindo 1978

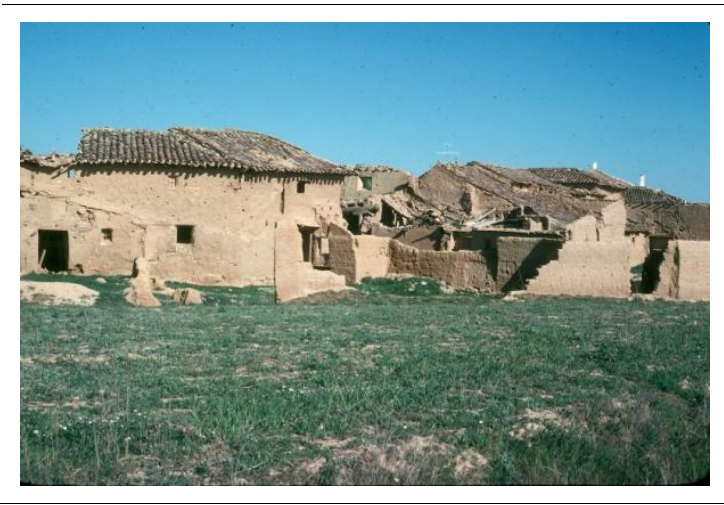
salida de población sobreenvejecida, que necesita la atención de unos servicios de los que carece en sus lugares de origen, y se encuentra impelida a trasladarse a las cabeceras comarcales o las capitales de provincia, en busca de la atención especializada en residencias o los cuidados familiares de hijas/os residentes en estas áreas. El resultado es que los espacios rurales regionales tienen una densidad de ocupación bajísima, con menos de 10 $\mathrm{hab} / \mathrm{Km}^{2}$, rayando la despoblación y con escasos visos de reversibilidad.

En un proceso en bola de nieve impulsado por los cambios económicos del conjunto nacional, la monoespecialización productiva de los espacios rurales y la implantación de un modelo agrario tecnificado, con una elevada productividad por activo agrario, vació nuestros campos de población joven, arrastrando consigo a los servicios y, de nuevo, al resto de la población.

Paisajísticamente, este proceso se traduce en un alto índice de ruina de gran parte del caserío tradicional marcado por el abandono, si bien es cierto que esta ruina afecta más a construcciones de carácter complementario (establos, paneras...) que a las propias viviendas. Un hecho relativamente sorprendente es el proceso, aparentemente contradictorio, de que la reducción de población no va acompañada de una reducción paralela del poblamiento, Se da, incluso, la paradoja de que núcleos en práctica despoblación asisten a la reconstrucción de una parte de sus edificaciones y a la construcción de otras nuevas, lo que obviamente está relacionado con algunas de las nuevas funciones de ocio de los espacios rurales, de las que hablaremos después.

\section{La pérdida de funcionalidad de elementos singulares del paisaje productivo tradicional: los palomares, lagares, las bodegas}

Efectivamente, el abandono y la ruina es más patente en aquellos elemen- 
tos cuyo origen y razón de existir está vinculado a las formas productivas del modelo tradicional. Todos nuestros pueblos y campos están cubiertos de restos, mejor o peor conservados de estas edificaciones que, en algunos casos, se vinculan en el imaginario colectivo como imagen de las llanuras castellanas: palomares, barrios de bodegas, chozos de pastores, molinos...

Figura 15. Torremormojón. Martín Ga- Figura 16. Palomares de cerámica. Eslindo años 70 cuela Tierras de Valid

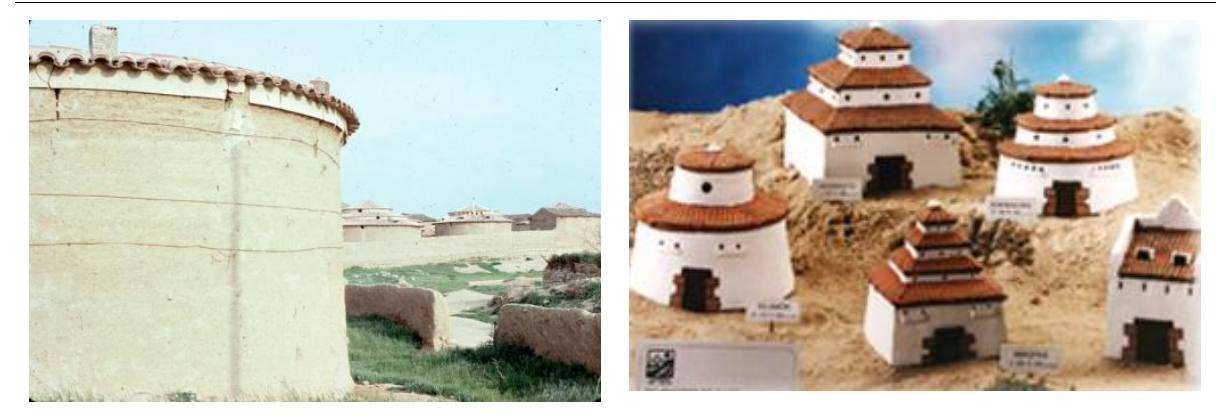

Figura 17. Tierra de Campos Valladolid.
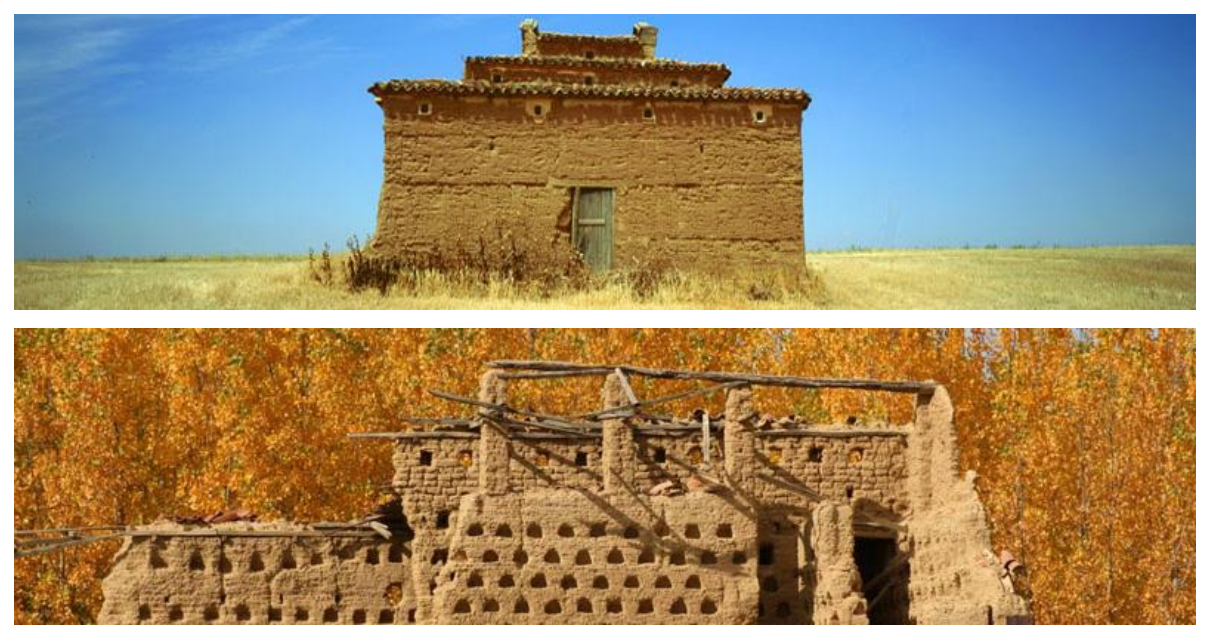

Fuente: Tierra de Campos Zona Norte de Valladolid. http://www.tierradecampos.com/ paisajes_y_naturaleza_en_tierra_de_campos.php consultado enero 2011

Los palomares, elementos fundamentales de la arquitectura popular de las llanuras castellanas y leonesas, cumplían dos funciones fundamentales en la agricultura tradicional: el abastecimiento de pichones como complemento de la dieta alimenticia y la producción de abono orgánico (palomina) muy valorado en el sistema de autoconsumo predominante hasta mediados del siglo 
XX. Propiedad generalmente de las familias de labradores más acomodadas de cada pueblo, constituyen un elemento presente en las afueras de prácticamente todos los núcleos de Tierra de Campos, donde, con sus imponentes forma circulares o cuadradas, rompen la horizontalidad de las vistas.

Figura 18. Barrio de Bodegas en Magaz (Palencia). Eugenio Baraja 2010

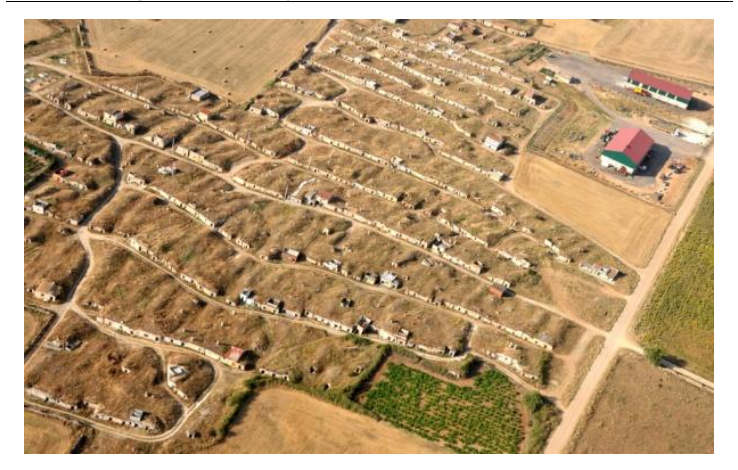

La mayor parte de los aproximadamente $\quad 10.000$ palomares existentes en la región ${ }^{2}$ se encuentran hoy abandonados ya que han perdido su funcionalidad $\mathrm{y}$, como consecuencia, se ven afectados por una imagen de ruina aún más dolorosa debido al deleznable material del que están construidos normalmente: el tapial. Sin embargo, paradójicamente, se han convertido en la imagen emblemática de las llanuras de Tierra de Campos, utilizados como modelo de artesanía de venta turística, imagen emblemática de programas de desarrollo rural, e incluso denominaciones de programas (Adri-Palomares en Zamora)

En situación similar se encuentran otros ejemplos de arquitectura popular de gran valor como son las bodegas. Excavaciones de galerías subterráneas en pequeños cerros y oteros, sus únicos elementos visibles están constituidos por las bocas de entrada y las chimeneas y respiraderos, construidas en distintos materiales según las zonas: adobe, piedra o ladrillo. Aparecen agrupadas formando barrios de bodegas muy característicos junto a los núcleos de población. En algunos casos singulares encontramos variantes de bodegas dispersas vinculadas a las viviendas y situadas en los sótanos de las mismas.

La desaparición de los viñedos destinados al autoconsumo familiar y local ha provocado la disfuncionalidad de estas edificaciones que, en gran medida, aparecen hoy abandonadas, algunas completamente derruidas o en proceso de derrumbe (con el peligro que eso supone no sólo de pérdida patrimonial sino también de arrastrar a todo el conjunto del barrio de bodegas o de algunos edificios de viviendas). Las que han conseguido mantenerse permanecen sostenidas por usos más vinculados al consumo de vino más que a su

\footnotetext{
${ }^{2}$ Según proposición no de Ley relativa a protección de palomares en la Comisión de Cultura de las Cortes presentada por la procuradora socialista, Ma Luz Martínez Seijo, 2009
} 
producción, ya que se han convertido en merenderos familiares, centros de peñas, negocios de hostelería...

Similares procesos de ruina por disfuncionalidad y de reconversión de usos para justificar su mantenimiento, encontramos en el caso de los molinos harineros, presentes en la mayor parte de los núcleos trigueros junto a los cursos de agua. En su mayor parte se hallan derruidos o son utilizados para otras funciones: restaurantes, alojamientos de turismo rural, museos y actividades culturales, merenderos familiares...Algunos de los mejor conservados han sido declarados Bien de Interés Cultural para garantizar su conservación.

Figura 19. Bodega en abandono y bodega reconvertida en merendero. Villatuelda (Burgos). M. Alario 2011

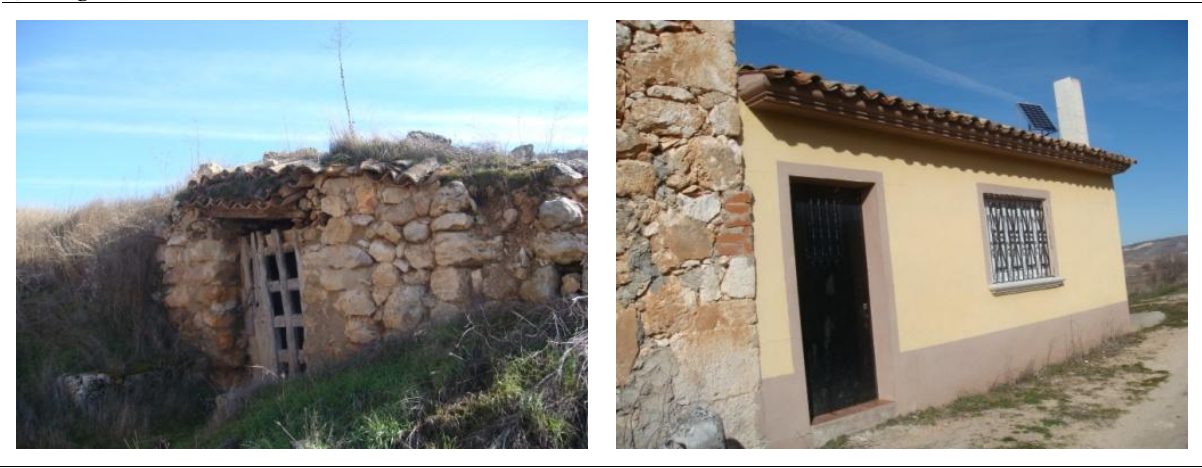

Figura 20. Chozos.

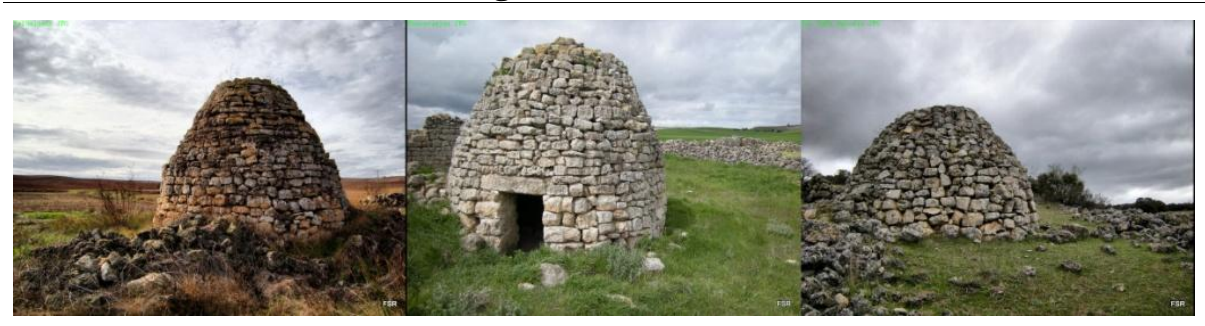

Fuente: http://valladolidenbici.files.wordpress.com/2009/11/valdelgada-rascaviejas-dc2aamanuela.jpg. Consultado enero 2011

Peor suerte han corrido otros ejemplos singulares de la arquitectura tradicional como los chozos. De planta normalmente circular, y ubicados en las áreas de trashumancia, eras y tierras de cereal o viñedo más alejadas de los núcleos, servían de refugio en las largas horas del pastoreo tradicional y para guardar aperos de labranza. Aunque su valor como construcción singular es indudable, ya que muchos de ellos estaban construidos con sistemas de falsa cúpula por aproximación de piedras sin argamasa, la mayor parte de ellos 
hoy han desaparecido, derruidos por efecto del abandono o la simple destrucción por considerarse un estorbo en los momentos álgidos de la mecanización de la agricultura.

\section{NUEVAS FUNCIONES, NUEVOS ELEMENTOS}

El desarrollo de nuevas funciones relacionadas con el ocio urbano ha provocado la aparición de nuevos elementos y la recuperación de otros, aunque no necesariamente con la misma función.

Figura 21. Restaurante El Molino, en Figura 22. Restaurante El Molino, en Saldaña (Palencia) Peñafiel (Valladolid)
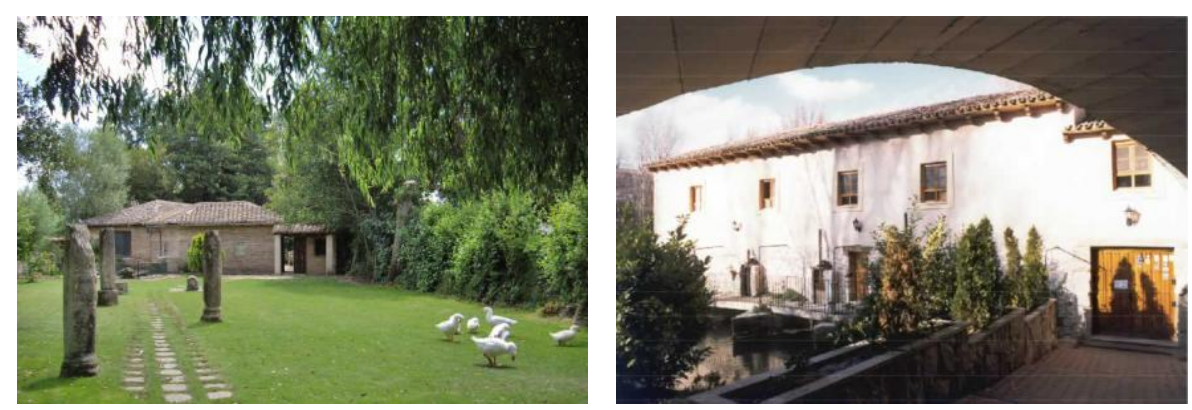

FUENTE: http://www.elmolinorestaurante.es y http://www.molinodepalacios.com/ El\%20 molino.htm, Enero 2011

Figura 23. Posada Real La casa del Figura 24. La Posada del Canal. VillaAbad. Ampudia (Palencia) nueva de San Mancio

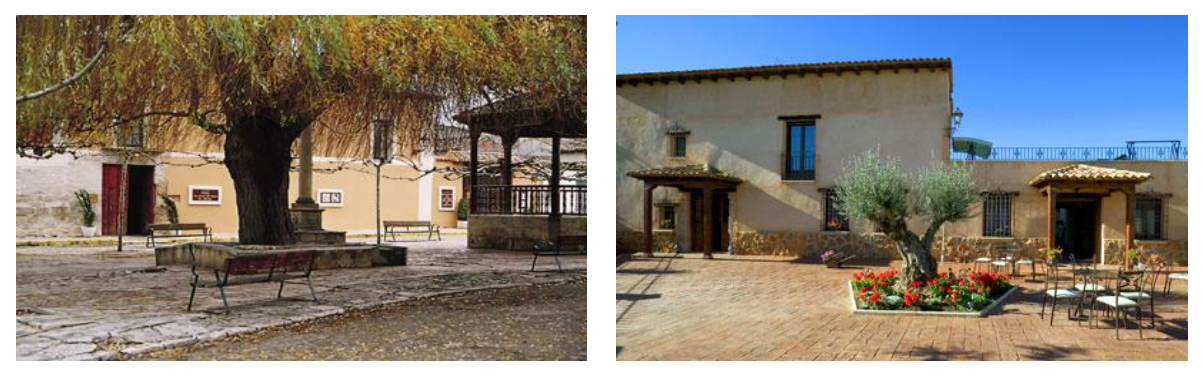

FUENTE: http://www.casadelabad.com/ y http://www.laposadadelcanal.com/. Enero 2011

Así, el vertiginoso crecimiento del turismo rural en las últimas dos décadas ha permitido y promovido la recuperación de un gran número de casas y edificaciones tradicionales con el objetivo de dedicarlas a alojamientos de turismos rural. Aunque se trata de un fenómeno mucho más desarrollado en espacios de montaña y áreas de especial valor patrimonial y/o paisajístico, también las llanuras de Castilla y León ha visto surgir este tipo de iniciativas 
en buena parte de sus pueblos. De esta forma, bien en viejas casas tradicionales o edificios más o menos singulares (Casa del Abad de Ampudia), los alojamientos destinados a la acogida de turistas, de origen fundamentalmente urbano, se han multiplicado en los últimos años hasta el punto de que constituyen una de las opciones económicas, junto con las actividades agraria, más dispersas en todos los espacios rurales de la comunidad. Desde un punto de vista paisajístico, aunque no tienen la entidad suficiente para modificar la imagen de abandono y deterioro de los pueblos, han contribuido poderosamente a su recuperación patrimonial.

Figura 25. La promoción de productos locales.

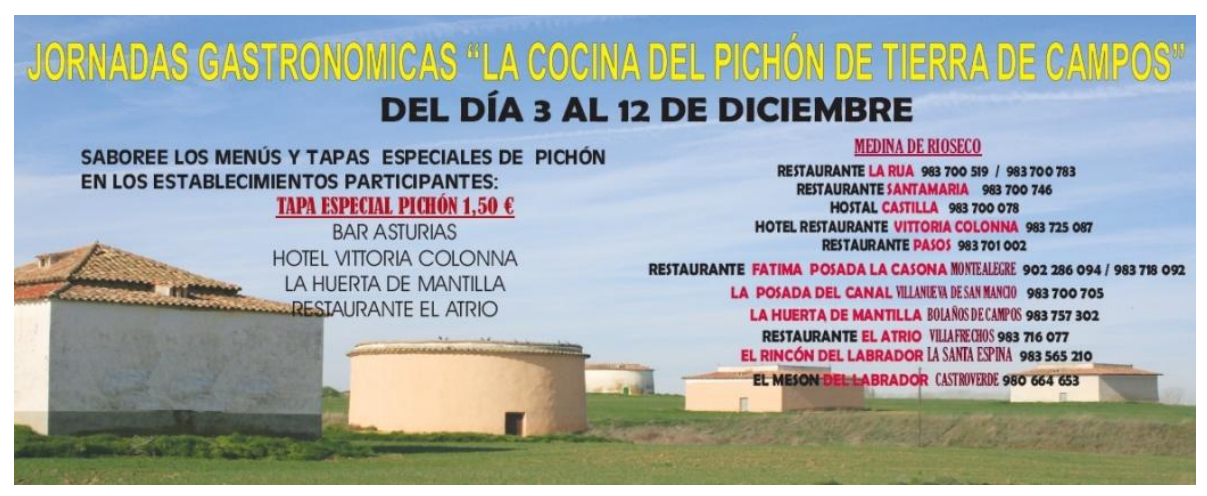

FUENTE: http://www.diputaciondevalladolid.es/turismo/actualidad/index.shtml?idboletin= 489 \&idarticulo $=76336 \&$ idseccion $=2490 \&$ fecha $=20101202$

Igual proceso de recuperación, pero con cambio de función, podemos apreciar en el caso de los palomares, algunos de los cuales son de nuevo funcionales, con orientación exclusiva para la producción de pichones que se han convertido en productos imprescindibles de la gastronomía turística (incentivada por iniciativas como, por ejemplo, la semana gastronómicas de Tierra de Campos en torno al pichón, que han alcanzado ya su XIV edición en 2010). Pocos cambios morfológicos, aunque fundamentales desde el punto de vista funcional, derivan de la conversión de antiguas explotaciones agrarias en centro de turismo activo vinculados sobre todo con la educación ambiental y el ocio infantil, como ocurre en el caso de la finca Las Cortas de Blas en Valladolid, así como con el desarrollo de actividades ecuestres en el entorno de las capitales.

En menor medida, las modificaciones paisajísticas derivan de la construcción de nuevas edificaciones con fines también de ocio y turismo, destacando los nuevos tipos de alojamientos como albergues o camping. Especial interés por la novedad que implican, tiene los nuevos equipamientos deporti- 
vos tipo los campos de golf como el de Villarrín de Campos (junto a Villafáfila), Arévalo o los de áreas periurbanas como Fuensaldaña, Grijota...

Con todo, lo más llamativo es el mantenimiento y la renovación de los núcleos de población vinculada a su principal función en la actualidad: la residencia temporal de personas que aún considerándose vecinas del pueblo sólo residen en él durante una parte del año o, los más numerosos, "hijos del pueblo" que ejerciendo lo que Cabero denomina "ocupación temporal del territorio" constituyen la pieza

Figura 26. Campo de golf Villarrín de Campos

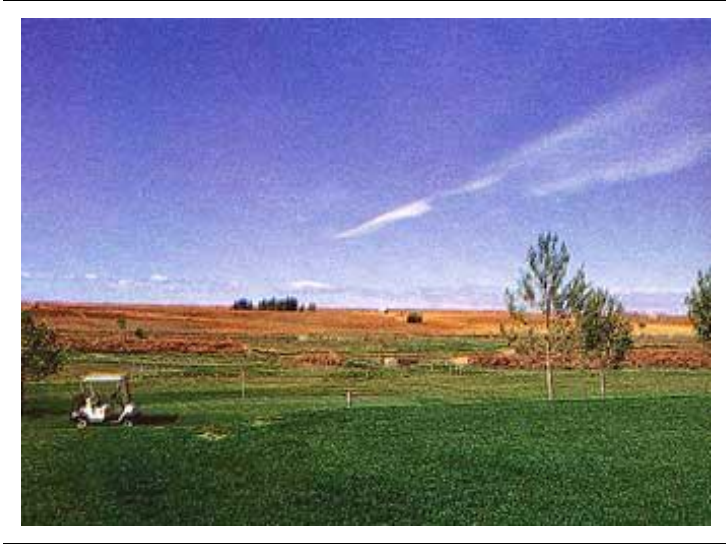

FUENTE: http://www.golfspain.com/esp/campos_info. asp?idCampo $=163$ fundamental del mantenimiento del caserío.

Puntualmente, el desarrollo de la nueva función asignada a los espacios rurales como productores de energía, ha generado la aparición de elementos singulares con una fuerte huella paisajística. Parques eólicos y huertos solares salpican las culminaciones de los páramos y las parcelas antes productoras de cereal. Cambio de producción, cambio de uso, cambio de propiedad, en algunos casos, que están generando no poca controversia sobre su rentabilidad, oportunidad e impacto en el paisaje.

\section{CONCLUSIONES}

La homogeneidad y simplificación que caracteriza los paisajes agrarios de las llanuras cerealistas de Castilla y León, son el resultado de un proceso en el que se entremezclan factores derivados de su estructura física con los más fundamentales de especialización productiva.

La progresiva integración de los espacios y las economías locales en los marcos nacionales e internacionales van convirtiendo en disfuncionales muchos elementos fundamentales en los modelos agrarios anteriores. El ritmo de adaptación o desadaptación funcional va determinando el mantenimiento, el abandono y la desaparición de formas singulares de estos paisajes tradicionales. El desarrollo de nuevas funciones en los espacios rurales, provoca la recuperación de viejos elementos para nuevos usos. Incluso, asistimos a 
la aparición de nuevos elementos paisajísticos que, fundamentalmente, están relacionados con las actividades de ocio y segunda residencia para consumidores urbanos.

Los paisajes actuales de las llanuras cerealistas de secano de Castilla y León son, pues, el resultado de su historia reciente pero, como todos los paisajes, son la antesala de los paisajes futuros ya que el paisaje no es, de ningún modo, estático ni permanece más allá del instante en que lo percibimos.

\section{BIBLIOGRAFÍA}

Alario Trigueros, M. (1991): Significado espacial y socioeconómico de la concentración parcelaria en Castilla y León. Ministerio de Agricultura, Pesca y Alimentación, Serie Estudios $n^{\circ} 60$

ÁLVAREZ JIMÉNEZ G. (dir) (2007): Informe Nacional sobre el estado de la cuestión de la biodiversidad en el medio agrario. D.G. para la Biodiversidad, Ministerio de Medio Ambiente.

Benito Martín, F. (2005): «El sistema medieval de asentamientos en Castilla y León». Arqueología y Territorio Medieval $\mathrm{n}^{\circ} 12.2,57-74$

BlanCo ABRIL, J. (2003): Nuestros bosques en Castilla y León. Su historia y evolución. Junta de Castilla y León, León.

BLÁZQUEZ JIMÉNEZ, A. (2010): http://www.viajesyviajeros.com/articulos/ odioalarbol.htm, Consultado diciembre 2010

CASCOS MARAÑA, C. (1987): «La compleja y variada configuración del relieve», en Manero Miguel, F. y Cabo Alonso, A.: Geografía de Castilla y León vol 3. Ed. Ámbito, Valladolid, 8-43

CAScos MARAÑA, C. (1992): «La configuración general del relieve», en MANERO Miguel, F. y CABo Alonso, A.: Geografía de Castilla y León vol 10. Ed. Ámbito, Valladolid, 8-9.

FORD, R. (2004): Cosas de España. Aventuras de un inglés por la Península Ibérica a mediados del siglo XIX. Ediciones B.

García Simón, A. (1999): Castilla y León según la visión de los viajeros extranjeros. Junta de Castilla y León, Salamanca.

GuerRa Velasco, J.C. y Alario Trigueros, M. (2011): «Árboles, montes y campos: los Montes de Torozos», pp 240-263, en Molinero, F.; OJEDA, J.F. y TORT, T. (coords.): Los paisajes Agrarios de España, Ministerio de Medio Ambiente, Medio Rural y Marino, $606 \mathrm{pp}$.

LÓPEZ LÓPEZ, A. y SANZ LÓPEZ, C. (1985): «Desarticulación espacial y calidad de vida en Castilla y León». Revista de Estudios Agro-sociales n ${ }^{\circ}$ 132, 9-41

Molinero Hernando, F. (1988): Vinos y viñedos de Valladolid, Cuadernos Vallisoletanos n ${ }^{\circ}$ 41, Caja de Ahorros Popular de Valladolid.

Ortega CANTERo N. (2002): «Paisaje e identidad nacional en Azorín». Boletín de la Asociación de Geógrafos Españoles, $\mathrm{N}^{\circ}$. 34, 2002, 119-130

ORTEGa CANTERo N. (2009): «Paisaje e identidad. La visión de Castilla como paisaje nacional (1876-1936)». Boletín de la Asociación de Geógrafos Españoles $\mathrm{n}^{\circ}$ $51,25-49$ 
PEÑA SÁnChez, M, (1987): Tierra de Campos. La integración de un espacio rural en la economía capitalista. Ed. Universidad de Valladolid y Caja de Ahorros y Monte de Piedad de Salamanca. Valladolid.

SÁNCHEZ ZURRO, D.: (1987): «Las estructuras agrarias tradicionales», en MANERO Miguel, F. y CABo Alonso, A.: Geografía de Castilla y León vol 4. Ed. Ámbito, Valladolid, 8-43

Reglero De LA Fuente, C. (1998): «Los despoblados bajomedievales en los Montes de Torozos: jerarquización del poblamiento y coyuntura económica». Revista Edad Media, no 1. 183-218. 